\title{
Academic branding: erythema $a b$ igne and use of laptop computers
}

\author{
David Botten MD, Richard G.B. Langley MD, Amanda Webb BSc
}

See related clinical image by Beleznay and colleagues, available at www.cmaj.ca

A 20-year-old female university student presented with a two-month history of asymptomatic pigmentation in a net-like distribution, isolated to the front thighs (Figure 1). She was otherwise healthy, apart from having recently completed a sixmonth course of isotretinoin for acne. She had no history of trauma to the front of the thighs, and her only medication was an oral contraceptive. On further questioning, however, she admitted to longstanding daily use of a laptop computer positioned atop her thighs.

This appearance is consistent with a diagnosis of erythema $a b$ igne. The benign, reticular pattern of hyperpigmentation occurs with direct repeated exposure to heat sources, such as heating pads, and has been found in up to $3 \%$ of the population. ${ }^{1}$ Heat is thought to induce epidermal damage along superficial blood vessels, causing deposition of hemosiderin in a net-like distribution. Most instances result from repeated exposure (lasting one to several hours) of the skin to heat. ${ }^{2.3}$ Erythema ab igne can appear as early as two weeks or as late as one year following the onset of heat exposure, depending on the intensity of the heat and the presence of clothing between the skin and the heat source. ${ }^{3}$ Recently, the heat from laptop computers has been implicated. ${ }^{3}$

Other than the permanent removal of the heat source from the skin, no further treatment is required. The skin changes usually clear spontaneously in several weeks to months, if the repeated exposure to heat is discontinued. For more severe $\because$ cases, topical 5 -fluorouracil cream or laser can be used. ${ }^{4}$ Rarely, skin cancer can occur at the site of erythema ab igne. ${ }^{5}$

From Dalhousie Health Services (Botten), Dalhousie University; and the Department of Dermatology, QEII Health Sciences Centre (Langley, Webb), Dalhousie University, Halifax, NS

CMAJ 2010. DOI:10.1503/cmaj.091868
With the widespread use of laptop computers, erythema ab igne may become more common. This condition is easily preventable with improved knowledge of the potential hazards of use of laptop computers.

This article has been peer reviewed.

Competing interests: None declared.

\section{REFERENCES}

1. Siragusa M, Schepis C, Palazzo R, et al. Skin pathology findings in a cohort of 1500 adult and elderly subjects. Int J Dermatol 1999;38:361-6.

2. Tan S, Bertucci V. Erythema ab igne: an old condition new again. CMAJ 2000;162:77-8.

3. Bilic M, Adams BB. Erythema ab igne induced by a laptop computer. J Am Acad Dermatol 2004;50:973-4.

4. Dissemond J, Grabbe S. Erythema ab igne. Intern Med J 2008;38:675

5. Hewitt JB, Sherif A, Kerr KM, et al. Merkel cell and squamous cell carcinomas arising in erythema ab igne. Br J Dermatol 1993;128:591-2. 